\title{
Health care in the North: what Canada can learn from its circumpolar neighbours
}

\section{T. Kue Young MD PhD, Susan Chatwood BScN MSc}

$\Gamma$ he perception of Canada as a nation with a polar region is gradually changing with the emergence of pressing public policy issues such as climate change, resource development, endangered wildlife and sovereignty disputes. These issues have given rise to Canada's Northern Strategy (www.northernstrategy.gc.ca /index-eng.asp), which focuses on issues such as environmental heritage, economic and social development, sovereignty and devolution of governance. ${ }^{1}$ Canada not only has a polar region, it is part of a circumpolar neighbourhood. In terms of health care, Canada may well benefit from looking to its circumpolar neighbours for partnerships, context and direction as it works to promote health equity throughout its northern regions.

The creation of the Arctic Human Health Expert Group within the Arctic Council in 2009 provides an international and policy-based forum for issues of concern to human health to be discussed in a circumpolar context. It promotes the exchange and dissemination of knowledge for improving health.

In Canada, the design and delivery of health services for the North have been oriented mostly along a north-south axis. Less attention has been given to circumpolar (i.e., north-north) perspectives. The predominance of north-south partnerships has resulted in fragmented administrative and operational services, with Nunavut often being served from regional centres in Ontario, the Northwest Territories being served from Alberta, and Yukon being served from British Columbia. Inuit people in Iqaluit, Nunavut, would have much more to gain if their service providers looked for collaboration in Nuuk, Greenland, rather than in Ottawa, when exploring best practices for prevention, primary care services or research.

Given the historical, jurisdictional and political complexities of the current system, it is worthwhile to examine health and health care in northern Canada from a circumpolar perspective and highlight lessons that may be learned from such partnerships.

\section{Understanding the circumpolar context}

Defining what constitutes "circumpolar" can be controversial. An inclusive definition would be membership in the Arctic Council, which comprises the United States, Canada, Denmark (with its self-governing territories of Greenland and the Faroe Islands), Iceland, Norway, Sweden, Finland and Russia. In this article, we define northern Canada as the three northern territories. Unless otherwise specified, all statistical data cover the period from 2000 to 2004 . $^{2}$

The extent to which northern regional issues occupy the attention of national governments is likely influenced by the proportion of the country's population residing in the North. The northern territories of Canada constitute less than $0.5 \%$ of the total population of Canada. Alaska's population is less than $0.5 \%$ of the United States', and Greenland's population is only $1 \%$ that of Denmark's. In contrast, a much higher proportion of the population of Norway (10\%), Sweden (6\%), Finland (12\%) and Russia (5\%) reside in their northern regions.

Northern Canada has a total population of just over 101000 and a population density of only 0.03 people $/ \mathrm{km}^{2}$. There are few cities (none with a population greater than 25000 ) and many widely scattered small settlements with poorly developed infrastructure. It is further differentiated from the rest of Canada by its territorial status and diverse governance powers. In Scandinavia, almost all of Finland and Norway,

\section{- Ker POINTS}

- Substantial disparities in health status exist across circumpolar countries and regions.

- Circumpolar regions have different models of health care delivery for remote communities and indigenous people.

- Health sciences research has lagged behind other disciplines in the Arctic.

- Improving health and health care in Canada's North requires a reorientation toward circumpolar partnerships to share best practices and build evidence-based policies.
Completing interests: See end of article for competing interests.

This article has been peer reviewed.

Correspondence to: Dr. T. Kue Young, kue.young@utoronto.ca

CMAJ 2011. DOI:10.1503 /cmaj.100948 
including their capital cities, lie north of the 60th parallel. There are few specifically "northern" programs; instead, national models tend to prevail. Arctic Russia is similar to northern Canada in its geography and climate, but it has taken a different path of development during decades of Soviet industrialization, collectivization, urbanization and internal migration. Yet, tensions between regions and "the centre" would be familiar to Canadians. ${ }^{3}$ With these facts in mind, one can see why a university with a medical school can exist in Troms $\varnothing$, Norway, far above the Arctic Circle, but not in the capital of any of Canada's territories.

Inhabiting the circumpolar regions are diverse ethnic groups, including many indigenous groups, several of which cross international boundaries, such as the Aleut, Inuit, Gwich'in, Athabaskans and Sami. Whereas indigenous people are a substantial minority in Alaska (20\%), Yukon (25\%) and Finnmark (30\%), they constitute about half of the population of the

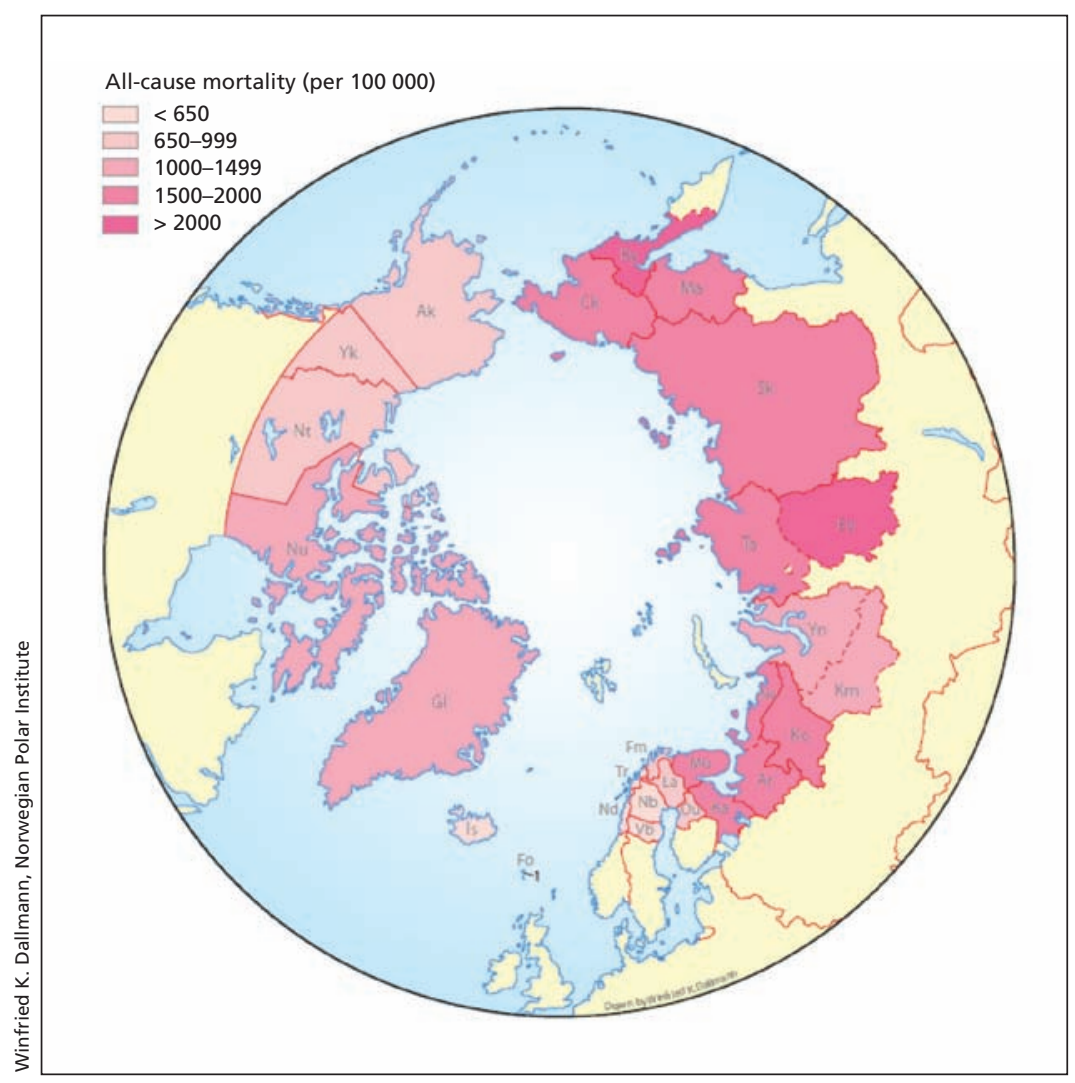

Figure 1: All-cause age-standardized mortality per 100000 population in circumpolar regions. ${ }^{2}$ Mortality rates have been standardized to the European Standard Population. $\mathrm{AO}=$ Autonomous Okrug (district or region), Ak = Alaska, $\mathrm{Ar}=$ Arkhangelsk Oblast, $\mathrm{Ck}=$ Chukotka $\mathrm{AO}, \mathrm{Fm}=$ Finnmark , Fo = Faroe Islands, Ev = Evenki AO, GI = Greenland, IS = Iceland, $\mathrm{Ka}=$ Kareliya Republic, $\mathrm{Km}=$ KhantyMansi AO, Ko = Komi Republic, Ky = Koryak AO, La = Lappi, Ma = Magadan Oblast, $\mathrm{Mu}=$ Murmansk Oblast, $\mathrm{Nb}=$ Norrbotten, $\mathrm{Nd}=$ Nordland, $\mathrm{Ne}=$ Nenets $\mathrm{AO}, \mathrm{Nt}=$ Northwest Territories, $\mathrm{Nu}=$ Nunavut, $\mathrm{Ou}=$ Oulu, Sk $=$ Sakha Republic, $\mathrm{Ta}=$ Taymyr AO, $\mathrm{Tr}=\mathrm{Troms}, \mathrm{Vb}=$ Västerbotten, $\mathrm{Yk}=$ Yukon, $\mathrm{Yn}=$ YamaloNenets AO.
Northwest Territories and the overwhelming majority in Nunavut and Greenland (> 85\%). In none of the autonomous regions of Arctic Russia, where the traditional homelands of indigenous people are located, do indigenous people form the majority. Disparities in health and social conditions between indigenous and nonindigenous populations exist in all countries, although to various degrees. In recent decades, international cooperation has strengthened among indigenous people's organizations, which recognize the value of circumpolar partnerships in promoting their people's well-being. ${ }^{4}$

\section{Health status}

Life expectancy at birth is a commonly used summary health indicator in international comparisons. Alaska's overall life expectancy at birth is the same as that of the United States, but it is about five years lower among Alaska Natives. In Canada's territories, the values decline as the proportion of Aboriginal people increases, such that the life expectancy at birth is 11 years lower in Nunavut than in all of Canada. In Fennoscandia, the overall life expectancy differs little from the value in its northern region. Russia is experiencing an unprecedented health crisis, with the life expectancy among males being less than 60 years nationally and in some of its northern regions. In the circumpolar regions, the difference in values between the region with the best life expectancy at birth (Iceland) and the region with the worst (Koryakia in Russia) is 29 years for men and 21 years for women. A similar pattern is observed for all-cause mortality (Figure 1), infant mortality and other health indicators. ${ }^{5}$ These indicators highlight vulnerabilities and disparities through the lifespan and result from a multitude of factors common across national borders.

As indicated by the program of the 14th International Congress on Circumpolar Health in July 2009 in Yellowknife, Northwest Territories, health issues of concern include food security, infectious diseases, mental health, chronic diseases, and maternal and child health. ${ }^{6}$

A more detailed discussion of health status across circumpolar regions may be found in the compendium "Circumpolar Health Indicators" and in the book Health Transitions in Arctic Populations. ${ }^{5}$

\section{Health determinants}

An association between socio-economic determinants and health outcomes is well recognized in many populations and is also ob- 
served in the circumpolar North. The disparities in health status between indigenous and nonindigenous peoples can be attributed in large part to these social inequalities. For example, the incidence of tuberculosis in circumpolar regions has been found to decrease as the proportion of adults with postsecondary education increases (Figure 2). ${ }^{2}$ In northern Canada, income, education and employment status of nonindigenous people are better than the national average. However, as the proportion of indigenous people increases from Yukon to Nunavut, the gap in socio-economic determinants increases between the territories and the rest of Canada. ${ }^{5}$

The association between per capita health expenditures and health outcomes, such as life expectancy, forms an inverted U-shaped pattern (Figure 3). Russian regions have low expenditures and poor health status; at the other extreme, regions such as Nunavut and Alaska (and the United States as a whole) fail to achieve better health outcomes despite their high level of health expenditures. Nordic countries and regions seem to achieve excellent health outcomes with relatively modest health expenditures. Of course, any implied association between health expenditures and outcomes, as with comparisons of various health outcome indicators across national borders, presupposes generally standardized public health problems and challenges. This is not the case across circumpolar regions. There are complex socio-economic, historical, geographic and cultural factors that need to be taken into account before we can infer causality and understand the underlying mechanisms at play.

\section{Health care and health policy}

Fundamental differences in the political systems of the circumpolar countries affect the way health care is organized. Canada, the United States and Russia are federal states, with constitutionally defined division of authority between the national government and other levels of government. The Nordic countries are unitary states that have a national ministry of health that delegates functions of health service delivery to regional and local governments. The Faroe Islands and Greenland are quasi-independent states in domestic affairs. Although their governments are heavily subsidized by Denmark, their health care systems do not have a "higher" authority in Denmark to which they report, or from which they receive program funding.

In the circumpolar North, countries fall into three categories according to their national health care systems: the United States, with its strong role for the private sector and its relatively high level of per capita health expenditures (more than $15 \%$ of the gross domestic product [GDP]); Canada and the Nordic countries, with their predominantly publicly funded systems and similar levels of health expenditures (about 10\% of the GDP); and Russia, where public funding of the health care system is higher than in the United States but lower than in Canada and the Nordic countries, but where the level of health care spending is extremely low (about 5\% of the GDP).

Compared with Canada's per capita health care expenditures as a whole, Yukon's expenditures are 1.3 times greater, the Northwest Territories' 1.7 times greater and Nunavut's 2.5 times greater. ${ }^{7}$ Nunavut's per capita expenditures are the highest in the world, and health care alone consumes almost $30 \%$ of the territory's GDP. Such a high level of resourcing is by no means the norm in the circumpolar North. Alaska's expenditures are only 1.2 times those of the United States, the northern regions of the Nordic countries are indistinguishable from the their southern regions, and Greenland's per capita expenditures are $70 \%$ those of Denmark. Only in various Siberian republics and regions do we see per capita expenditures that reach as high as nine times the Russian national level.

In addition to political and economic factors, the differences in health expenditures could be explained by the different models of health service delivery in remote areas. Factors such as workforce skill and mix, provision of public health and primary care services, geographic remoteness, and service models for indigenous populations have a substantial influence on the effectiveness and efficiency of the health care system.

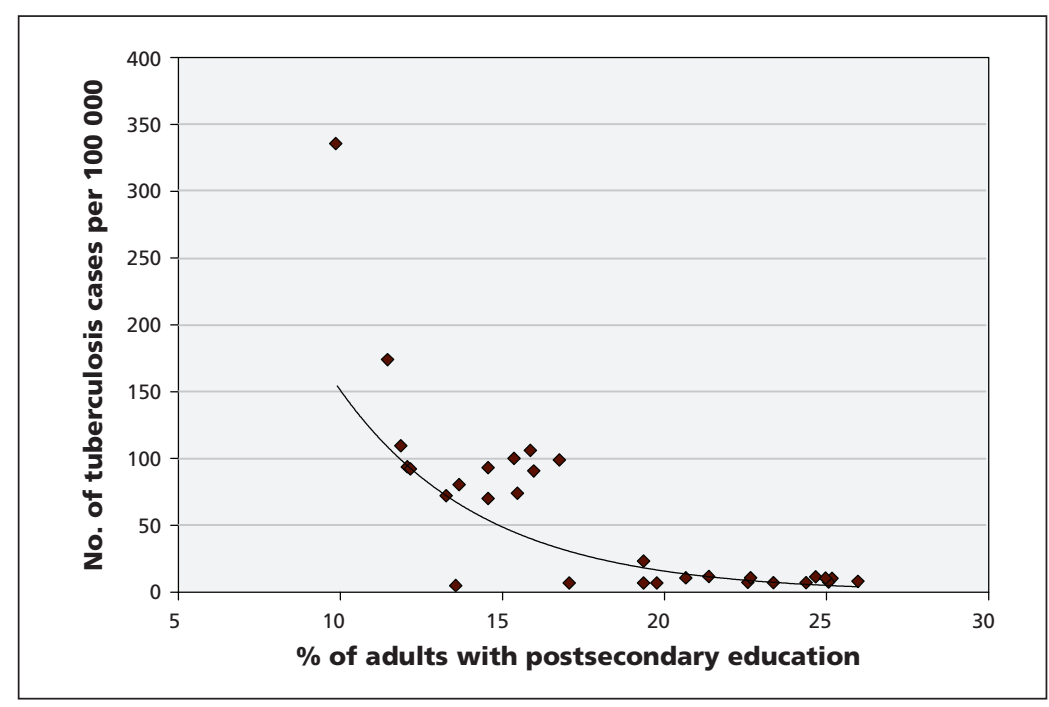

Figure 2: Association between incidence of tuberculosis and proportion of adults with postsecondary education in circumpolar regions. ${ }^{2}$ 
Alaska Natives have a federally funded and tribally administered health care system separate from that for non-Native Alaskans. Alaska pioneered the training and deployment of villagebased Community Health Aides, who provide primary care supported by physicians based in regional centres. In Canada, remote communities are staffed by nurse practitioners, community health representatives and, in some cases, midwives. Nurse practitioners practise in an extended role, with family physicians in regional centres and specialist services in larger centres providing support. Air transportation and telecommunication provide the critical link between communities, regional centres and tertiary referral centres. Greenland has opted for a system of small hospitals staffed by up to five general medical officers in all of its main towns. Scandinavian countries have a well-developed system of general practitioners based in health centres serving assigned and territorially defined populations. The Soviet health care system developed a middle-level cadre of medical practitioners called feldschers; in remote areas, mobile medical teams have served reindeer-herding brigades. The end of the Soviet Union was followed by upheavals in the health care system in the northern regions and nationally; further health reforms are still in progress. ${ }^{8}$

Attention to the outstanding disparities and the need for separate health care services for indigenous populations varies across regions. The health care system for Alaska Natives is self-contained, from community facilities to the 150-bed multispecialty Alaska Native Medical Center in

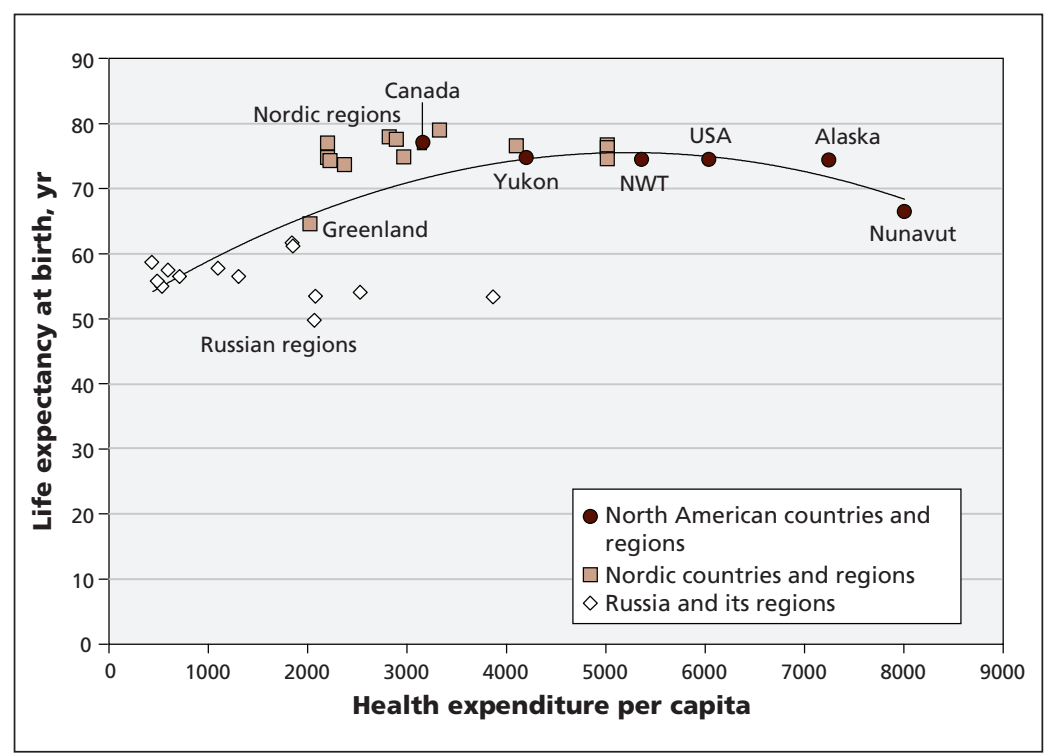

Figure 3: Association between health expenditures per capita and life expectancy at birth among males in circumpolar countries and regions. ${ }^{2}$ Note: Health expenditures are expressed in US\$ purchasing power parities. NWT = Northwest Territories.
Anchorage. In the Canadian North, the territorial governments administer most health services, except in Yukon, where some programs and services have been transferred to First Nations communities. Although the movement to selfdetermination for indigenous people has advanced the most in Nunavut and Greenland, selfgovernment and control of health services have not translated into better health outcomes. The association between indigenous self-government, community control of health services and health equity is complex and influenced by a multitude of political, social and economic factors. A study of such associations in remote First Nations communities has recently been reported. ${ }^{9}$ Similar studies are needed in circumpolar regions.

In 1995, Norway developed a national plan for health and social services for the Sami, one of the indigenous people of northern Europe. In Sweden and Finland, however, the Sami are not singled out for "redressing" inequalities or identified as a group with special health needs, unlike other groups such as immigrants and refugees who are approaching a significant proportion of the population, especially in urban Sweden. ${ }^{10}$ This has not escaped the criticism of Sami organizations, which emphasize their need for culturally specific health programs. However, one wonders whether the relative lack of attention to the health needs of indigenous people in Nordic countries is because of the existence of broader social programs and supports outside the health care system. As noted earlier, the Sami do not experience the same disparities experienced by other indigenous groups. If our mainstream national programs are doing a good job of addressing disparities across government departments, is there still a need for parallel systems targeting specific groups? Are parallel systems the best way to respond to cultural needs? Circumpolar comparisons may provide valuable insight for such complex issues. There is a need for concurrent analysis of services outside the health care system that affect disparities in health outcomes, such as child care, early childhood education, prevention services and social safety nets.

\section{Health research}

In recent years, Canada's federal government has increased funding for Arctic research, including the proposed High Arctic Research Initiative. ${ }^{11}$ The recently concluded International Polar Year (2008/09) marked the first time that health and the human dimension received the same attention as the natural sciences. Canada led the world in allocating $\$ 150$ million in research funding to projects, and early results are starting to appear. ${ }^{12}$ 
How circumpolar health research is organized varies from country to country. Some countries have established central polar research programs, specialized institutes and dedicated core funding. In other countries, including Canada, dispersed researchers operate in isolation and have to compete with other disciplines for funds. This diversity creates challenges for international collaboration. ${ }^{13}$ The lack of an Arctic science policy in Canada has been criticized by some scientists; ${ }^{14}$ however, it is perhaps more important to ask how Canada's overall science and technology strategy ${ }^{15}$ can best meet the needs of Arctic science. Regions such as the Northwest Territories have developed a science agenda that is adapted for northern needs. ${ }^{16} \mathrm{~A}$ bibliometric analysis of the output of Arctic science in Canada by research field shows that, compared with environmental sciences, the outputs of the health sciences are low, highly specialized and have a low impact in terms of citation counts. ${ }^{17}$ A review of research licences issued in the Northwest Territories from 2004 to 2007 showed that, of 1063 licences issued, only 27 were for health research projects. ${ }^{18-20}$ This supports the view that health sciences research has lagged behind other disciplines in the North.

New approaches to conducting health research in the North have emerged in recent years. Increased capacity is being built through the creation of northern-based research institutes, data centres (e.g., the Circumpolar Health Observatory, www.circhob.circumpolarhealth.org) and university affiliations. These initiatives promote an environment for critical thinking and position Canada to respond to needs for circumpolar health. ${ }^{21}$ Northern researchers, health authorities and policy-makers have become more involved in building research capacity, leading research projects and setting priorities. Research programs that are close to community partners and decision-makers are priorities. These include health service delivery, monitoring of population health, community-based methods and the socioeconomic determinants of health. The International Polar Year has provided a boost to circumpolar collaborations. The momentum needs to be sustained by national funding agencies to support coordinated and strategic Arctic health research.

\section{What we can learn}

Several questions emerge from circumpolar comparisons: Why are some northern populations healthier than others? What are the policy implications for such disparities, and are there potential strategies to redress them? It is important to distinguish between measures that the health care system can offer (e.g., human resources management, use of information technology and organizational change) and problems that cannot be fixed by the health care system alone (e.g., the broader social determinants of health).

Answers to such questions are more likely to emerge if we extend our traditional north-south orientation in policy development and service delivery toward enhancing circumpolar partnerships. Through such partnerships, we can share best practices, build evidence-based health care and improve social policies to address health determinants in the North. Existing forums can be used, such as national circumpolar health societies and the Arctic Council, where international indigenous peoples' organizations also participate fully. The creation of the Human Health Expert Group within the Arctic Council in 2009 showed that policy makers recognize the need to address health issues. This expert group is well positioned to synthesize and disseminate evidence that is informed by circumpolar perspectives.

The current prominence of Arctic issues provides a window of opportunity for Canadian health policy-makers, service providers and researchers to strengthen circumpolar collaboration and partnerships, analyze our commonalities and differences, and adopt best practices to improve our northern health care system and the health of the population.

\section{References}

1. Government of Canada. Canada's Northern Strategy: our north, our heritage, our future. Ottawa $(\mathrm{ON})$ : Minister of Public Works and Government Services Canada; 2009. Available: www .northernstrategy.ca/cns/cns-eng.asp (accessed 2010 Oct. 21).

2. Young TK. Circumpolar health indicators: sources, data, and maps. Int J Circumpolar Health 2008;(Suppl 3):1-128. Available: www.ijch.fi/CHS/CHS_2008(3).pdf (accessed 2010 Oct. 21).

3. Goode JP. The rise and fall of regionalism in Russia. In: Heaney D, editor. The territories of the Russian Federation 2010. London (UK): Routledge; 2010. p. 3-15.

4. Arctic Council Indigenous Peoples Secretariat. Shaping change, adapting to change: indigenous peoples and the Arctic Council. Copenhagen (Denmark): The Secretariat; 2002. Available: www .arcticpeoples.org/Newsletter/Documents/brochure.pdf (accessed 2010 Oct. 21)

5. Young TK, Bjerregaard P, editors. Health transitions in arctic populations. Toronto $(\mathrm{ON})$ : University of Toronto Press; 2008.

6. Chatwood S. Summary: 14th International Congress on Circumpolar Health: Securing the IPY legacy, from research to action. Yellowknife, July 11-16, 2009. Int J Circumpolar Health 2009; 68:414-5.

7. Canadian Institute of Health Information. National health expenditure trends 1975-2008. Ottawa (ON): The Institute; 2008. p. 125-7.

8. Tompson W. Healthcare reform in Russia: problems and prospects. Organisation for Ecomonic Co-operation and Development Economics Department Working Paper no. 538. Paris (France): Organisation for Economic Co-operation and Development; 2007.

9. Lavoie JG, Forget EL, Prakash T, et al. Have investments in onreserve health services and initiatives promoting community control improved First Nations' health in Manitoba? Soc Sci Med 2010;71:717-24.

10. Hassler S, Kvernmo S, Kozlov A. Sami. In: Young TK, Bjerregaard $\mathrm{P}$, editors. Health transitions in arctic populations. Toronto (ON): University of Toronto Press; 2008. p. 166-8. 


\section{HYDROMORPH Contin'qi2h}

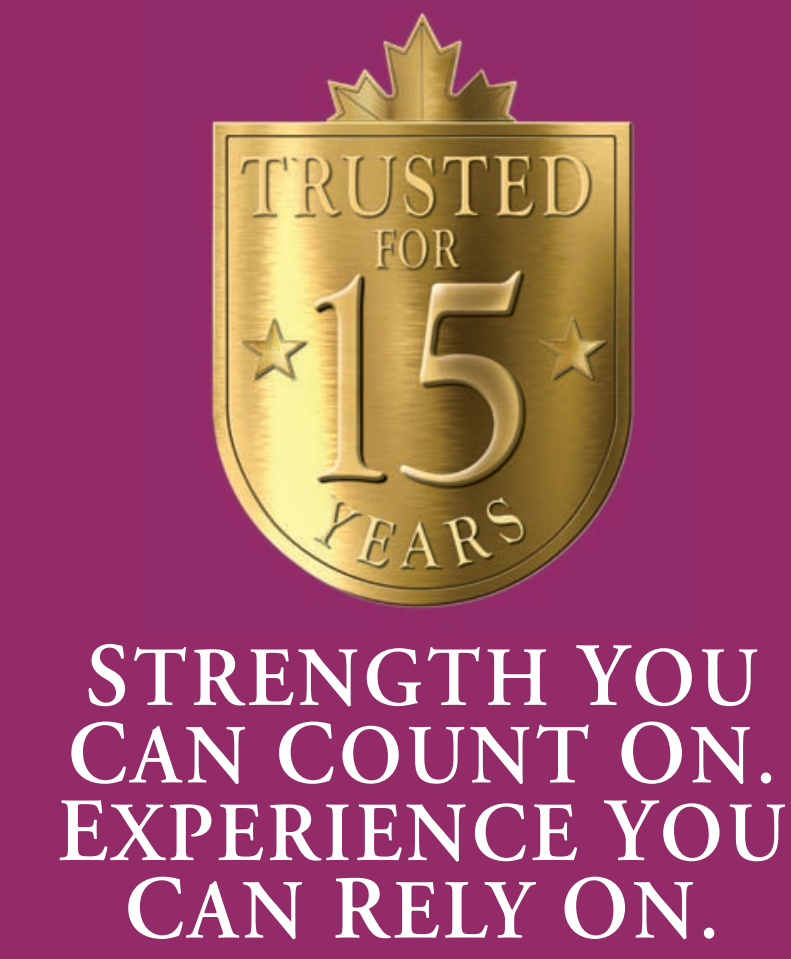

Hydromorph Contin $^{\circledR}$ is indicated for the relief of severe chronic pain requiring the prolonged use of an oral opioid preparation.

Side effects are similar to other opioid analgesics. The most frequently observed are asthenic conditions, confusion, constipation, dizziness, lightheadedness, nausea, sedation, sweating and vomiting. Dosage limitations may be imposed by adverse effect. If they occur, please refer to prescribing information. Warning: Opioid analgesics should be prescribed and handled with a high degree of caution appropriate to the use of a drug with strong abuse potential. Patients should be cautioned not to consume alcohol while taking Hydromorph Contin ${ }^{\circledR}$, as it may increase the chance of experiencing dangerous side effects. Hydromorph Contin ${ }^{\circledR} 18 \mathrm{mg}$ capsules and higher are for use in opioid tolerant patients only. There is a potential for fatal respiratory depression in patients not previously exposed to similar equianalgesic doses of an opioid analgesic. Hydromorph Contin ${ }^{\circledast}$ capsules or capsule beads should not be chewed, crushed or dissolved since this can lead to rapid release and absorption of a potentially fatal dose of hydromorphone. Product monograph available on request.

Hydromorph Contin ${ }^{\circledR}$ capsule beads may be sprinkled on cold, soft food.

\section{'HYDROMORPH Contin'q12h \\ Controlled release hydromorphone capsules}

A trusted choice for severe chronic pain

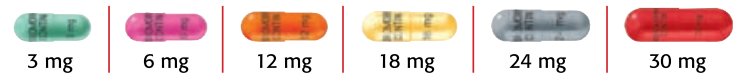

Initiation at $3 \mathrm{mg} \mathrm{q} 12 \mathrm{~h}$ or calculate the approximate daily oral hydromorphone dosage that should provide equivalent analgesia. See Product Monograph Table 1, Opioid Analgesics: Approximate Analgesic Equivalences.

11. International Expert Panel on Science Priorities for the Canadian Arctic Research Initiative. Vision for the Canadian Arctic Research Initiative: assessing the opportunities. Ottawa $(\mathrm{ON})$ Council of Canadian Academies; 2008. p. 2-3. Available: www .scienceadvice.ca/en/assessments/completed/canadian-arctic.aspx (accessed 2010 Oct. 21)

12. Canadian International Polar Year Program Office. The IPY Canada Early Results Workshop; 2010 Feb. 16-18; Ottawa (ON). Available: www.ipy-api.gc.ca/pg_IPYAPI_056-eng.html (accessed 2010 Oct. 21).

13. Petersen HK. The Arctic: A model for science cooperation? In: Abele F, Courchene TJ, Seidle FL, et al., editors. Northern exposure: peoples, powers and prospects in Canada's North. Montréal (QC): Institute for Research on Public Policy; 2009. p. 169-83.

14. England J. Canada needs a polar policy. Nature 2010;463:159.

15. Industry Canada. Mobilizing science and technology for Canada's advantage. Ottawa (ON): Public Works and Government Services Canada; 2007. Available: www.ic.gc.ca/eic/site /ic1.nsf/eng/h_00856.html (accessed 2010 Oct. 21).

16. Government of the Northwest Territories. Building a path for northern science. Government of the Northwest Territories' science agenda. Inuvik (NWT): Aurora Research Institute; 2009. Available: www.nwtresearch.com/Libraries/Research\%20Agenda /Building\%20a\%20Path\%20for\%20Northern\%20Science.sflb (accessed 2010 Oct. 21)

17. Côté G, Picard-Aitken M. Arctic research in Canada: a bibliometric analysis. Report submitted to Indian and Northern Affairs Canada. Montréal (QC): Science-Metrix; 2009. p. 11-12.

18. Aurora Research Institute. Compendium of research in the Northwest Territories 2004-2005. Fort Smith (NT): The Institute. Available: www.nwtresearch.com/resources/publications /Compendia.aspx (accessed 2010 Oct. 21).

19. Aurora Research Institute. Compendium of research in the Northwest Territories 2006. Fort Smith (NT): The Institute. Available: www.nwtresearch.com/resources/publications/Compendia.aspx (accessed 2010 Oct. 21).

20. Aurora Research Institute. Compendium of research in the Northwest Territories 2007. Fort Smith (NT): The Institute. Available: www.nwtresearch.com/resources/publications/Compendia.aspx (accessed 2010 Oct. 21).

21. Chatwood S, Young TK. A new approach to health research in Canada's North. Can J Public Health 2010;101:25-7.

Competing interests: Susan Chatwood is the executive and scientific director of the Institute for Circumpolar Health Research and president of the Canadian Society for Circumpolar Health. She received a grant (no. NS1100031) from Health Canada for the development of the Circumpolar Health Observatory. Kue Young is the Canadian representative and co-chair of the Arctic Human Health Expert Group.

Affiliations: From the Dalla Lana School of Public Health (Young, Chatwood), University of Toronto, Toronto, Ont.; the International Network for Circumpolar Health Research (Young), Toronto, Ont.; the Institute for Circumpolar Health Research (Chatwood), Yellowknife, NWT; and the Canadian Society for Circumpolar Health (Chatwood), Yellowknife, NWT

Contributors: Both authors were responsible for the conception and design of the article, contributed equally to drafting and revising the article for important intellectual content and approved the final version to be published. 